\title{
SOFT-TISSUE BALANCE AND ALIGNMENT IN MEDIAL UNICOMPARTMENTAL KNEE ARTHROPLASTY
}

\author{
ROGER H. EMERSON JR, WILLIAM C. HEAD, PAUL C. PETERS JR \\ From the Southwestern Medical School, Dallas
}

\begin{abstract}
We reviewed two similar groups of patients with medial osteoarthritis of the knee treated by unicompartmental arthroplasty. The group receiving an Oxford meniscal-bearing implant, with no medial release, showed significantly better mechanical alignment than that receiving a fixed-bearing implant. Undercorrection, with its ominous mechanical implications, was much more common with the fixed-bearing design. Over-correction was rare and was seen in both designs about equally. Degenerative stenosis of the intercondylar notch was common and appeared to put the anterior cruciate ligament at risk of rupture, especially after correction of the varus deformity.

We consider that postoperative leg alignment and soft-tissue balance after unicompartmental knee replacement are determined more by the implant design and the surgical technique than by any variation in soft-tissue contracture. Release of the medial collateral ligament is not necessary for realignment, but a generous notchplasty is often needed to allow normal anterior cruciate ligament function.
\end{abstract}

The correction of axial leg alignment by total knee replacement has mechanical consequences (Kettelkamp and Chao 1972; Johnson, Leitl and Waugh 1980; Hsu et al 1989) and it has been shown that better postoperative alignment of a unicompartmental replacement is related to better clinical function (Kennedy and White 1987; Larsson, Larsson and Lundkvist 1988) and to longer implant survival (Barrett and Scott 1987; Kozinn, Marx and Scott 1989).

In bicondylar total knee arthroplasty, the techniques for the correction of deformity by soft-tissue retensioning and releasing are generally accepted (Merritt, Conaty and Dorr 1987) but little has been published about softtissue management in unicompartmental knee arthroplasty. It is not clear whether the techniques for bicondylar replacement apply to unicompartmental operations, and the role of the anterior cruciate ligament $(\mathrm{ACL})$ is not well defined.

We have therefore reviewed our results with two

R. H. Emerson Jr, MD, Associate Clinical Professor of Orthopaedic Surgery

W. C. Head, MD, Associate Clinical Professor of Orthopaedic Surgery P. C. Peters Jr, MD, Instructor of Orthopaedic Surgery

Southwestern Medical School, Dallas, Texas, USA

Correspondence should be sent to Dr Roger H. Emerson Jr at 8230 Walnut Hill Lane, Suite 106, Dallas, Texas 75231-4170, USA

(C) 1992 British Editorial Society of Bone and Joint Surgery $0301-620 X / 92 / 6419 \$ 2.00$

J Bone Joint Surg [ Br] 1992; 74-B :807-10 different unicompartmental replacements, comparing the restoration of alignment and soft-tissue balance.

\section{PATIENTS AND METHODS}

We studied two consecutive groups of patients having medial unicompartmental knee replacements. The first group of 39 had a retrospective review of 42 Robert Brigham fixed-bearing prostheses (Johnson \& Johnson, New Brunswick, New Jersey), the second group of 21 had a prospective review of 27 Oxford meniscal-bearing replacements (Biomet Ltd, Bridgend, Wales).

All the patients had osteoarthritis, and all the operations were performed by the authors. The criteria for unicompartmental replacement in all patients were medial pain, medial joint-space narrowing, a normal lateral compartment and a minimally involved patellofemoral compartment. The final decision to proceed was made after the knee had been opened.

Measurements of knee alignment were made on standing anteroposterior radiographs taken with a 3-foot film cassette. We considered that postoperative varus or neutral positions showed under-correction, and that valgus angulation of over $10^{\circ}$ showed over-correction. We also drew the mechanical axis of the joint, as a line from the centre of the femoral head to the centre of the talus, and classified its relation to the tibial plateau (Kennedy and White 1987): zones 1 and 2 were in the medial compartment ; zone $C$ at the centre of the plateau; and zones 3 and 4 in the lateral compartment.

Operations. Each of the implants has its unique features, 


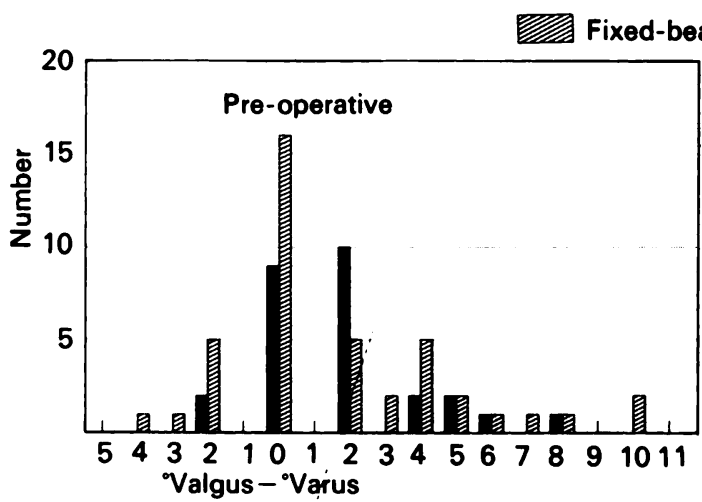

Fig. 1

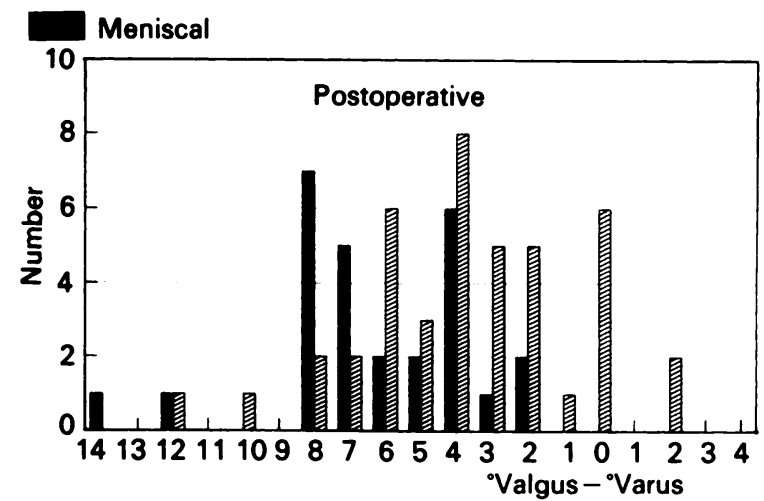

Fig. 2

Bar graphs showing pre-operative and postoperative alignments.

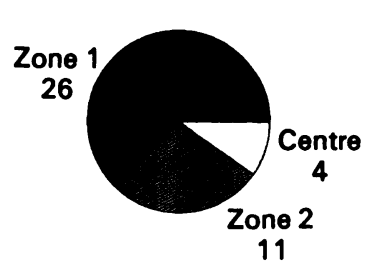

Pre-operative

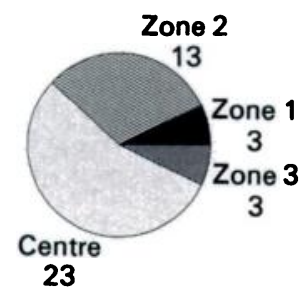

Postoperative

Fig. 3

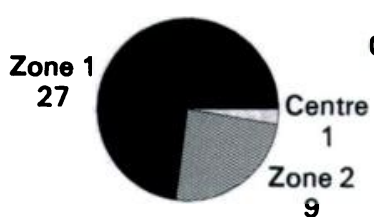

Pre-operative

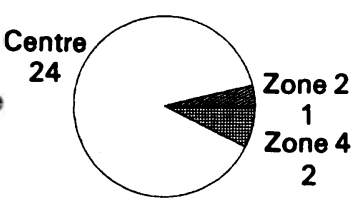

Postoperative

Fig. 4

Pie charts showing pre-operative and postoperative alignments of fixed-bearing knees (Fig. 3) and of meniscal-bearing knees (Fig. 4) by the position of the weight bearing axis (zones 1 and 2 medial, zone 3 lateral).

but all were placed through a medial surgical approach, removing any osteophytes, and performing the same sequence of bone resection. The tibia was cut first, and then the posterior femoral cut was made with an assessment of the flexion gap. Finally, the distal femoral resection was performed. Alignment during the operation was assessed by a long external rod, using a femoral head marker placed under radiographic control. Soft-tissue tension was tested manually.

The Oxford meniscal implant was placed according to the technique of Goodfellow et al (1988), preserving the intact ACL and performing no ligament release. Alignment was restored, and the medial collateral ligament (MCL) and ACL retensioned by inserting the largest possible meniscal bearing to fill the extension and flexion gaps. Acceptable ligament tension allowed free gliding of the polyethylene meniscal component, with no opening of the joint at either full extension or $90^{\circ}$ flexion. Intercondylar osteophytes which appeared to impinge on the ACL in any position of the knee were completely removed.

The Robert Brigham implant was placed according to the recommendations of Thornhill (1986) and Scott (1990) aiming to allow 1 to $2 \mathrm{~mm}$ of opening of the joint in full extension. In flexion the tension was accepted provided that the tibial component did not lift off. Medial soft-tissue release was performed when the compartment was judged to be too tight. Intercondylar osteophytes were removed only when they appeared to impinge on the tibial component during the range of motion.

\section{RESULTS}

Before operation, the alignments of the two groups of patients were very similar. There was no significant difference between the tibiofemoral angles of the two groups using the two-sample $t$-test $(\mathrm{p}=0.87)$ and the Kruskal-Wallis test $(p=0.56)$ or the location of the mechanical axis by tibial zone (Fisher's exact test: $\mathrm{p}=0.39$ ).

In the meniscal-bearing series, the average preoperative alignment was $2^{\circ}$ varus $\left(8^{\circ}\right.$ varus to $2^{\circ}$ valgus), and the mechanical axis was through the medial side of the joint in all cases. The fixed-bearing series also showed an average pre-operative alignment of $2^{\circ}$ varus $\left(10^{\circ}\right.$ varus to $3^{\circ}$ valgus). In four of these patients the mechanical axis was through the centre of the joint, and in the remainder it was through the medial side (Fig. 1).

After operation, the meniscal series had an average alignment of $6^{\circ}$ valgus $\left(0^{\circ}\right.$ to $12^{\circ}$ valgus $)$ as shown in Figure 2, with no knees in varus angulation. Two knees $(7 \%)$ had more than $10^{\circ}$ of valgus. The mechanical axis was through the centre of the plateau in 24 knees, just medial to the centre (zone 2) in one, and through the 


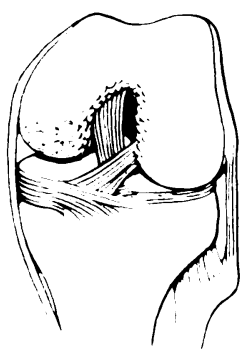

Fig. 5a

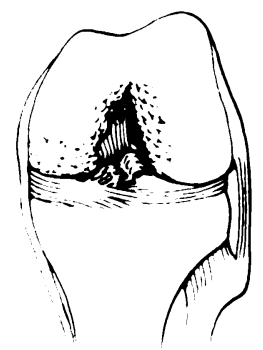

Fig. 5b

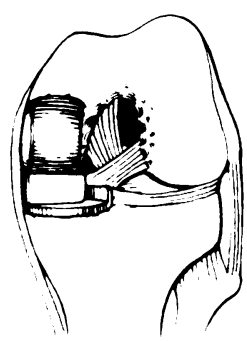

Fig. 5c
Figure 5a - Early osteoarthritis with small osteophytes in the intercondylar notch. Figure $5 \mathrm{~b}$ - In more advanced notch stenosis, there is a triangular configuration and loss of height of the notch. The varus deformity and resultant cruciate laxity protect the $A C L$ from attrition. The risk is greatest in extension. Figure 5c-After notchplasty and arthroplasty there is unrestricted excursion of the cruciate ligaments, with restoration of ACL length and tension.

lateral side of the lateral compartment (zone 4) in the two over-corrected knees as shown in Figure 3. No ligament releases were done in this group.

The average postoperative alignment in the fixedbearing series was $4^{\circ}$ valgus ( $2^{\circ}$ varus to $12^{\circ}$ valgus) as shown in Figure 2 . Two knees $(5 \%)$ were in $2^{\circ}$ of varus, and four knees $(10 \%)$ were in neutral alignment, giving a $15 \%$ incidence of under-correction. The mechanical axis was through the centre in $23 \mathrm{knees}$, and medial to centre (zone 2) in 13 (Fig. 4) In the two knees still in varus, the mechanical axis crossed zone 1 . Only one knee had more than $10^{\circ}$ valgus alignment, but in another three the mechanical axis passed through zone 3 , just lateral to the centre of the plateau.

The difference in mean alignment between the two groups, $4^{\circ}$ valgus as compared with $6^{\circ}$ valgus, was significant using the $t$-test $(\mathrm{p}=0.0007)$ and the KruskalWallis test $(\mathrm{p}=0.007)$. The correction obtained was also significantly different between the two groups when corrected for pre-operative alignment. The meniscal design produced significantly more correction than the fixed-bearing design ( $t$-test, $\mathrm{p}=0.007$; Kruskal-Wallis test, $\mathrm{p}=0.006$ ). The middle $50 \%$ of postoperative alignment values fell between $6^{\circ}$ and $2^{\circ}$ valgus for the fixed-bearing group and between $8^{\circ}$ and $4^{\circ}$ valgus for the meniscal group. Of the meniscal knees, $89 \%$ were centred on zone analysis, while of the fixed-bearing knees only $55 \%$ were centred and $38 \%$ were too medial, a significant difference on the likelihood ratio chi-squared test $(\mathrm{p}=0.002)$.

In the fixed-bearing group two knees had subperiosteal release of the medial capsule and of the deep and superficial MCL; their postoperative alignments were $5^{\circ}$ and $7^{\circ}$ valgus respectively.

Eleven of the 42 fixed-bearing knees showed a measurable non-parallelism between the femoral and tibial articulating surface on standing radiographs, which must have produced high contact pressures. These 11 knees had an average postoperative alignment of $5^{\circ}$ valgus $\left(0^{\circ}\right.$ to $12^{\circ}$ valgus). Two of them developed nonparallelism only on weight-bearing, showing that it was due to excessive soft-tissue laxity, although neither had any symptoms of instability. There was no lack of parallelism in the meniscal series. Even when there was some obliquity of the meniscal component the design ensured that the articulating surfaces remained congruent.

Intercondylar notch. In the prospective meniscal-bearing group, we noted a variable degree of osteophyte formation in the intercondylar notch. Narrowing of both the height and width of the notch created a variable stenosis (Fig. 5) and this osteophyte formation converted the normal inverted U-shape to a more pointed configuration (Anderson et al 1987). Impingement of these osteophytes on the ACL was worse in full knee extension, but the varus deformity which accompanied medial compartment osteoarthritis appeared to help to protect the ACL by increasing its laxity. When the varus deformity had been corrected by implant insertion, however, the ligament became tense and impinged on the lateral and superior femoral notch osteophytes. In no case did the notch stenosis prevent correction of the varus deformity, but the removal of the osteophytes allowed normal alignment of the ACL with no impingement (Fig. 5).

\section{DISCUSSION}

We conclude that medial soft-tissue release for the correction of varus deformity is not necessary during unicompartmental arthroplasty for medial compartment osteoarthritis. After any necessary removal of osteophytes, the restoration of normal soft-tissue tension by the insertion of the appropriately sized implant can consistently restore axial alignment within the physiological range of $5^{\circ}$ to $10^{\circ}$ valgus. This was not achieved with the fixed-bearing design.

Over-correction is often discussed as a problem in unicompartmental replacement (Laskin 1978; Barrett and Scott 1987; Kozinn et al 1989; Stulberg and Stulberg 1990), but we had only five cases in our 69 knees, two in the meniscal group and three in the fixed-bearing group, all in the absence of ligament release. We feel that the mechanical consequences of over-correction have probably been overrated.

By contrast, under-correction was relatively common in our fixed-bearing group ( $38 \%$ ), but only one of 27 meniscal knees was under-corrected. Under-correction probably has a much worse effect on tibial loading than over-correction (Kettelkamp and Chao 1972; Johnson et al 1980), but the recommendation to leave some medial tibial opening in extension (Thornhill 1986; Scott 1990) favours such under-correction and can also produce softtissue instability and non-parallelism of the articulating surfaces, both of which are unfavourable. Non-parallelism is a recognised problem with the fixed-bearing implants of this design (Kozinn et al 1989; Emerson and Head 1991).

It is clear that under-correction of a unicompartmen- 
tal replacement does not result from soft-tissue contracture, which needs release, but from failure to restore normal tissue tension. Correction of knee alignment appears to depend more on the implant design and insertion technique, than on any soft-tissue pathology.

Better alignment and soft-tissue tension, however, must create a tighter overall fit of the articulating surfaces, and equal flexion and extension gaps are therefore important. Mismatch of gaps, usually too tight in flexion, may lead to binding of the components, with eccentric loading and loss of range of movement (Thornhill 1986).

The role of the ACL in unicompartmental arthroplasty has not been widely studied, but it is probably an important factor for prolonged function, as shown by Goodfellow and O'Connor (1992). Isolated ACL division produces increased anteroposterior laxity, most marked in extension (Markolf, Mensch and Amstutz 1976), and Berchuck et al (1990) have found unbalanced muscular forces in the form of a quadriceps-avoidance gait during walking in the absence of a functioning ACL.

The attritional rupture of the $A C L$ as a result of degenerative notch stenosis may be a more frequent cause of unicompartmental implant failure than has been appreciated, although the relationship has been noted (Marmor 1980; Anderson et al 1987; Souryal, Moore and Evans 1988). Arnold et al (1979) reported that most ACL ruptures occur with the knee in extension, and it follows that notch stenosis will increase ACL impingement. We recommend that a generous widening and lengthening notchplasty should be performed as part of all unicompartmental arthroplasties.

No benefits in any form have been received or will be received from a commercial party related directly or indirectly to the subject of this article.

\section{REFERENCES}

Anderson AF, Lipscomb AB, Liudahl KJ, Addlestone RB. Analysis of the intercondylar notch by computed tomography. Am J Sports Med 1987; 15:547-52.

Amold JA, Coker TP, Heaton LM, Park JP, Harris WD. Natural history of anterior cruciate tears. Am J Sports Med 1979; 7:305-13.
Barrett WP, Scott RD. Revision of failed unicondylar unicompartmental knee arthroplasty. J Bone Joint Surg [Am] 1987: 69-A :1328-35.

Berchuck M, Andriacchi TP, Bach BR, Reider B. Gait adaptations by patients who have a deficient anterior cruciate ligament. $J$ Bone Joint Surg [ Am] 1990; 72-A :871-7.

Emerson RH, Head WC. Failure mechanisms of unicompartmental knee replacement: the impact of changes in operative technique and component design. Seminars in Arthroplasty 1991: 2:23-8.

Goodfellow JW, Kershaw CJ, Benson MK D'A, O'Connor JJ. The Oxford knee for unicompartmental osteoarthritis. J Bone Joint Surg $[\mathrm{Br}]$ 1988; 70-B:692-701.

Goodfellow J, O'Connor $\mathbf{J}$. The anterior cruciate ligament in knee arthroplasty: a risk factor with unconstrained meniscal prostheses. Clin Orthop 1992: 276:245-52.

Hsu HP, Garg A, Walker PS, Spector M, Ewald FC. Effect of knee component alignment on tibial load distribution with clinical correlation. Clin Orthop 1989; 248:135-44.

Johnson F, Leitl S, Waugh W. The distribution of load across the knee : a comparison of static and dynamic measurements. J Bone Joint Surg [Br] 1980; 62-B:346-9.

Kennedy WR, White RP. Unicompartmental arthroplasty of the knee: postoperative alignment and its influence on overall results. Clin Orthop 1987: $221: 278-85$.

Kettelkamp DB, Chao EY. A method for quantitative analysis of medial and lateral compression forces at the knee during standing. Clin Orthop 1972: 83:202-13

Kozinn SC, Marx C, Scott RD. Unicompartmental knee arthroplasty a 4.5-6-year follow-up study with a metal-backed tibial component $J$ Arthroplasty 1989; 4 Suppl:S1-10.

Larsson SE, Larsson S, Lundkvist S. Unicompartmental knee arthroplasty. Clin Orthop 1988; 232:174-81.

Laskin RS. Unicompartmental tibiofemoral resurfacing arthroplasty. J Bone Joint Surg [ Am] 1978; 60-A : 182-5.

Markolf KL, Mensch JS, Amstutz HC. Stiffness and laxity of the knee The contributions of the supporting structures: a quantitative in vitro study. J Bone Joint Surg [Am] 1976: 58-A :583-94.

Marmor L. Anterior cruciate destruction in osteoarthritis. Contemporary Orthopaedics 1980;2:590-1

Merritt P, Conaty JP, Dorr LD. Effect of soft tissue releases on results of total knee replacement. In: Rand JA, Dorr LD. Total arthroplasty of the knee. Proc Knee Society 1985-1986. Rockville, Maryland Aspen Publishers, 1987.

Scott RD. Robert Brigham Unicondylar Knee surgical technique Techniques Orthop 1990: 5:15-23.

Souryal TO, Moore HA, Evans JP. Bilaterality in anterior cruciate ligament injuries: associated intercondylar notch stenosis. Am J Sports Med 1988; $16: 449-54$.

Stulberg SD, Stulberg BN. Principles and techniques of unicompartmental knee arthroplasty: the MICROLOC Unicompartmental Total Knee System. Techniques Orthop 1990; 5:37-52.

Thormhill TS. Unicompartmental knee arthroplasty. Clin Orthop 1986 $205 ; 121-31$. 